\title{
SEMINAR ON THE PREPARATION OF RELIEF IN CASE OF DISASTER
}

From 22 to 28 April 1974, a Disaster Relief Training Course was held at Kuala Lumpur. It was organized by the Malaysian Red Cross Society in co-operation with the League of Red Cross Societies, represented by Mr. S. Kilde, director of the Relief Preparedness Bureau, Mr. Seveeratnam, regional delegate for Asia, and Mr. J. Weyand, relief operations officer. The seminar was attended by delegates from the National Societies of the following countries: Australia, Canada, India, Indonesia, Japan, the Republic of Korea, Malaysia, New Zealand, the Philippines, Singapore, Thailand and the Republic of Vietnam. Two ICRC delegates were present, Mr. F. Schmidt, head of the Logistics Division, and Mr. A. Tschiffeli, regional delegate for South-East Asia, who spoke about the organization of the Red Cross and the duties of the ICRC and the Central Tracing Agency.

Courses were held on subjects such as the co-ordination of intergovernmental relief organizations, the United Nations and other voluntary aid agencies; the League's responsibilities in case of disaster; various aspects of tropical medicine, and mass supply problems. They also comprised discussions and films on emergency relief. Two whole days were set aside for practical exercise by small groups.

On the latter occasion, a convoy of eighteen vehicles was mobilized (ambulances, a mobile clinic, large amphibious vehicles, jeeps, etc.). The participants themselves set up their camps. They slept in tents and thus actually led the existence of Red Cross workers engaged in disaster relief, the primary duty of the Red Cross, which must be ready at all times to help victims of natural disasters or warfare. 